\title{
A institucionalização da Medicina Legal no Brasil
}

\author{
The institutionalization of Forensic Medicine in Brazil
}

\author{
Ivan Dieb Miziara1, Carmen Sílvia M.G. Miziara², \\ Daniel Romero Muñoz ${ }^{3}$
}

"O passado existe para ser lembrado, para ajudar a compreender o presente e para pensar o futuro" - Eduardo Gonçalves

\begin{abstract}
Miziara ID, Miziara CSMG, Muñoz D. A institucionalização da Medicina Legal no Brasil. Saúde, Ética \& Justiça. 2012;17(2):66-74.

RESUMO: Os autores traçam um panorama da chegada da Medicina Legal no Brasil, desde sua introdução, por intermédio de Nina Rodrigues na Faculdade de Medicina da Bahia, passando pela vinda de Oscar Freire a São Paulo e a consequente criação da disciplina junto à Faculdade de Medicina e Cirurgia de São Paulo, futura Faculdade de Medicina da Universidade de São Paulo, até a institucionalização da mesma, realizada por seu principal discípulo Flamínio Fávero.
\end{abstract}

DESCRITORES: Medicina legal/história; Medicina legal/educação.; Educação de graduação em medicina/ história.

\footnotetext{
${ }_{1}^{1}$ Professor Titular da Disciplina de Medicina Legal e Deontologia Médica da Faculdade de Medicina do ABC.

${ }^{2}$ Médica do Departamento de Medicina Legal, Ética Médica e Medicina Social e do Trabalho da Faculdade de Medicina da Universidade de São Paulo.

3. Professor Titular do Departamento de Medicina Legal, Ética Médica e Medicina Social e do Trabalho da Faculdade de Medicina da Universidade de São Paulo.

Endereço para correspondência: miz@uol.com.br
} 


\section{INTRODUÇÃO}

A Medicina Legal remete a tempos imemoriais, quando a sociedade passou a depender de conhecimentos biológicos para a solução de conflitos de natureza judicial. Assim é que documentos ancestrais revelam inúmeros exemplos de associação entre a Medicina (representada pelos sacerdotes que invocavam poderes divinos por conta de sua estreita relação com as divindades) e o Direito. O primeiro Código penal de que se tem conhecimento data do século XVIII a.C, promulgado por Hamurábi da Babilônia, contendo já dispositivos relacionados a eventos ocorridos durante um tratamento médico. Um de seus artigos é ilustrativo de como essa relação se estabelecia: "Se um médico tratou um ferimento grave de um escravo de um homem pobre, com uma lanceta de bronze, e causou a morte do escravo, deve pagar escravo por escravo"1. A pena imposta aos médicos nesses casos variava de acordo com a importância do cidadão atingido, ainda que os juízes não fossem obrigados a ouvir os médicos sobre todas as questões a serem julgadas.

Como ensinava Afrânio Peixoto em relação a esta ordenação jurídica, "artigos estabelecem o exercício da medicina e da medicina veterinária, e até a responsabilidade dos médicos e cirurgiões"2. Sem dúvida, o Código de Hamurabi representa um marco essencial da prática médico-legal, assim como, na antiga Pérsia, as leis vigentes já estabeleciam uma classificação das lesões corporais baseada em critérios de gravidade, depois de uma análise médica ${ }^{2}$.

A seguir, vieram as leis de Manú, na Índia, durante o século $\mathrm{V}$ a.C, que, no seu capítulo VII, consignam para a pesquisa de certos crimes um exame pericial. Crimes sexuais, aborto provocado, adultério e bestialidade estavam nestas condições: antes do exame, o médico brahmane recitava orações e fórmulas védicas, invocando a divindade e jurando apenas dizer a verdade. Esse Código também proibia os testemunhos de loucos, débeis mentais, crianças e velhos, interdição esta que, no mundo ocidental, só irá aparecer com a Lei das XII tábuas, em 449 a.C, no Império Romano, e, com a Lex alemanorum, a classificação das lesões corporais por ordem de gravidade, com a finalidade de se arbitrar a multa a ser paga pelo agressor ${ }^{1}$.

Os hebreus também produziram avanços no campo médico-legal. Por exemplo: para um depoimento ser considerado válido eram necessários dois testemunhos. Além disso, contribuíram até nos primórdios da sexologia forense. Afrânio Peixoto cita que "no Deuteronômio cap. XII há os sinais da virgindade: o Cap. XXI trata da defloração e dá a solução dos panos manchados de sangue à dúvida do marido que acusa à mulher de desonestidade" - costume este, de origem árabe, que se tornaria popular em Nápoles com a exibição da camicia dell'onore, manchada de sangue do desvirginamento. Neste tópico, o rei Salomão era mais cético, talvez considerando a complacência himenal como regra, dizia: três coisas há difíceis de saber e uma impossível: o caminho da flecha no ar, o do peixe na água, o da lesma no rochedo... e o do varão na mulher"'.

A ciência (assim como a filosofia e a medicina do modo que as conhecemos) começa na Grécia. Aristóteles fixa em 40 dias a presença da alma no feto: o atentado contra ele no aborto devia levar em conta este fato, pois já se tratava de uma pessoa ${ }^{2}$. Hercules ${ }^{1}$ cita que a primeira menção ao um exame médico realizado em vítima de homicídio refere-se ao exame do corpo de Julio César por Antistius, no ano de $44{ }^{a} \mathrm{C}$, em que $\mathrm{O}$ médico constatou a presença de 23 golpes de punhal desferidos pelos agressores no Senado Romano, sendo que apenas um dos golpes foi mortal ${ }^{1}$. Por esta época, Plínio Antigo já falava sobre a responsabilidade dos médicos: Discunt periculus nostris et experimenta per mortem agunt ${ }^{3}$.

Em Roma, então, além da Medicina, já era presente o Direito. Os Códigos de Justiniano já têm, implícita, a Medicina Legal. No Digesto há este conceito, dizia Afrânio Peixoto: "Médici non sunt proprie testes, sed magis est judicium quam testimonium: não testemunham, ajuízam". É o princípio técnico da perícia, dizia ele ${ }^{2}$.

Uma lei de Numa Pompilio prescrevia a histerectomia na morte da mulher grávida: é a operação cesariana, de coedo, is... cortar: "César" vem daí, e não o oposto. Na Lei das Doze Tábuas já há a tutela dos incapazes e insensatos, associando-se a incapacidade à doença mental. No Digesto as parteiras são chamadas para o exame da gravidez, suposta ou duvidosa. As simulações de doenças são contempladas. Nas Pandectas e Novelas, trata-se do casamento, da impotência, da vitalidade, da separação de corpos etc.

Ainda no Império Romano, foi Justiniano que veio a reconhecer os médicos como testemunhas especiais em juízo, porém sem que os juízes fossem obrigados a ouvi-los. Determinação desse tipo somente será instaurada com a já citada Lex alemanorum e com as Capitulárias de Carlos Magno, nos casos de lesão corporal, infanticídio, suicídio, estupro, impotência etc. Esta é a Idade Média.

Entre idas e vindas, com períodos de refluxo 
e épocas de grande avanço, a Medicina Forense foi-se desenvolvendo aos solavancos. No século XI já existiam peritos-cirurgiões em Paris. Um decreto do papa Inocêncio III, em 1219, fala do exame dos ferimentos em juízo, denotando que isso já fosse algo habitual. O princípio da perícia, nesse tempo, é formulado pelos jurisconsultos: Quacumque in arte peritis credendum est.

Em 1374, os exames necroscópicos deixam a clandestinidade quando o papa concede à Faculdade de Medicina de Montpellier a primeira autorização para realizar necropsias para estudos anatômicos e clínicos. Somente em 1507, na Alemanha (pelo Código de Bamberg), a perícia médica em casos de mortes violentas se tornou obrigatória, assim como as perícias sexuais codificadas pelo papa Gregório XIII. Em direito, surge o axioma: medico creditur in sua medicina: tem fé publica o médico, nos assuntos médicos².

Com isso, a autopsia (e o termo aqui é usado propositalmente, tendo em vista as divergências que provoca entre aqueles que preferem necropsia. Não vemos muito sentido na polêmica, já que a medicina grega, de onde a palavra deriva, chamava autopsia à experiência direta, ou a primeira vista. Só depois é que "autopsia" ficou restrita à observação direta do cadáver, visão cuja referência era, neste caso, toda a perícia, visum et repertum. Mais tarde abriu-se o corpo para ver e observar. "Quem procura o sentido às palavras poderia piedosamente pensar que o homem de arte via-se, ou se revia, na sua miséria, como num espelho, olhando e observando o morto: pulvis es.... Autopsía, pois, e está muito bem", dizia mestre Peixoto ${ }^{2}$. Autopsia, pois.); mas, como dizíamos, com isso a autopsia é permitida e ordenada. A anatomia renasce, por isso, e se completa. A Medicina Legal adquire agora um corpo de doutrina.

O mesmo Afrânio Peixoto frisava: "é de 1575 o primeiro livro de Medicina Legal, o assunto, pelo menos, algumas páginas de Ambroise Paré num livro de cirurgia. 'Resta agora', dizia Paré, 'instruir ao jovem cirurgião a bem fazer um relatório à justiça, quando chamado a isso, seja por morte dos feridos, ou por impotência ou depravação de qualquer parte. Aí ele deve ser cauto, isto é, engenhoso, em fazer seu prognóstico, por causa do envenenamento das doenças, difícil de reconhecer... principalmente por causa da incerteza do assunto, no qual é empregada a arte da cirurgia'... E aludindo à consciência, à sinceridade, à isenção, conclui: 'porque os juízes julgam segundo o que se Ihes relata'. É a essência da perícia: o médico informante técnico do juiz. $\mathrm{E}$, quanto a esse médico, adstrito ao princípio imutável visum et repertum."‥ É, também, o início da "escola francesa" de Medicina Legal, que tem entre seus luminares, além de Pare, Lacassagne, Paul Brouardel e Tardieu.

Diferentemente da Europa, há poucos registros da presença da Medicina Legal no Brasil Colônia. A primeira escola de Medicina do país foi inaugurada na Bahia, no dia 18 de fevereiro de 1808 , oito dias antes da partida da família real para o Rio de Janeiro. Ela foi instalada no Hospital Real Militar, que ocupava as dependências do Colégio dos Jesuítas, no Largo do Terreno de Jesus. Ali, ainda não se realizavam perícias, e, mesmo o estudo da anatomia sobrevivia a condições precárias.

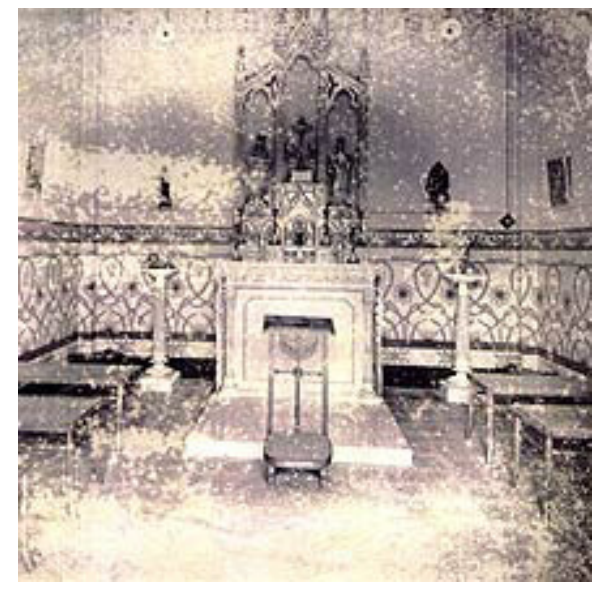

Figura 1 - Vista da Faculdade de Medicina da Bahia, fundada em 1808

Desse modo, o objetivo deste artigo é traçar um panorama da chegada da Medicina Legal ao Brasil e de sua institucionalização como disciplina autônoma.

\section{O PASSADO DA MEDICINA LEGAL NO BRASIL}

Para que possamos entender melhor a evolução da Medicina Legal brasileira, é imprescindível que, antes, façamos um mergulho no passado, para compreender as bases do processo que fez com que esta disciplina crescesse no país e se tornasse uma especialidade autônoma, com suas regras e metodologia próprias - a fim de melhor servir às necessidades da Justiça. Ou, como afirmava Agostinho de Souza Lima, "esta confraternização entre a Medicina e o Direito"4.

Por isso mesmo, o grande mestre Afrânio Peixoto advertia, em prefácio de sua obra magistral, que

É a Medicina Legal aplicação de conhecimentos científicos a misteres da Justiça. Não ciência 
autônoma, no sentido exato da expressão, mas conjunto de aquisições, de vária origem, para fim determinado. Se aquilo que se the atribue como próprio fica restrito, aumenta-se consideravelmente o que lhe importa, buscado em disciplinas diversas, para a aplicação do momento ${ }^{3}$.

\section{E, como dizia Souza Lima,}

é uma ciência de aplicação, cuja importância, porém, se impõe pela especialidade do fim a que se destina, como pela complexidade dos meios, pela extensão dos conhecimentos que exigem, e que constituem esses meios de alcançar aquele $\mathrm{fim}^{4}$.

\section{E Afrânio Peixoto aduzia:}

A especialização do perito não é por isso menos necessária, porque sua função exige justamente que adquira determinados conhecimentos e os saiba empregar na prática forense. Seu exercício é comparável ao do clínico, só possível após a aquisição global das ciências médicas. Apenas o círculo é mais dilatado, porque já o termo medicina é estreito para as preocupações da Medicina Legal. As ciências físicas e naturais, as ciências sociais já lhe emprestam suas noções e seus métodos ${ }^{2}$.

Tal afirmação, por si só, visionária para a época de lançamento de seu clássico "Medicina Legal" - no final dos anos 30 do século passado - propunha um novo futuro para a então jovem disciplina no Brasil:

Firme neste juízo, e escrevendo um livro didático para a instrução de futuros peritos e magistrados, evitei todos os ranços da antiga Medicina Legal, que se comprazia em velhas anedotas e especiosas suposições, tomada de medos pueris e sempre em guarda com reservas prudentes, esquecendo o fato exato de observação e desprezando o critério positivo da experimentação, para discutir possibilidades, comentar leis, produzir protestos vãos ${ }^{2}$.

Em outras palavras: mestre Afrânio, com grande clarividência, desprezava o costume anedótico da Medicina Legal de então e, a par da aquisição dos conhecimentos oriundos de outras disciplinas, propugnava, além da tradicional "observação" (uma das características básicas médico legais, traduzida no aforisma do visum et repertum), o fundamental "critério positivo da experimentação" - base para o desenvolvimento de qualquer ciência, principalmente as médicas.
A Medicina Legal no Brasil, com estrutura adequada e métodos próprios, é uma disciplina relativamente nova, se compararmos com outros países e com outros ramos da arte médica. Não estamos aqui, obviamente, falando de questões episódicas que se arrastam pela História com "H" maiúsculo, como a propalada necessidade de peritos em questões judiciais permeadas por dúvidas técnicas de natureza médica - como é descrito no Código de Hamurabi ou no Código Carolino de Carlos V, mas dos percalços que esta disciplina teve de percorrer até ser reconhecida como matéria própria e independente, seja na área médica seja na área do Direito. Como bem enfatizou Lima Drummond, ao prefaciar a obra seminal de Agostinho J. Souza Lima, outro prócer da Medicina Legal brasileira,

No $2^{\circ}$ congresso internacional de antropologia criminal, que se realizou em Paris, no ano de 1889 , Lacassagne, insistindo nas idéias que já havia expendido no Congresso de Roma, propugnou com brilhantismo pelo ensino da medicina legal nas faculdades de direito ${ }^{4}$.

Sim, já naquela época, cientistas do peso e do renome de um Lacassagne haviam de se debater contra o preconceito à relativamente nova disciplina, preconceito este eivado em afirmações tão tolas quanto ignorantes, como as de que a Medicina Legal não seria disciplina autônoma e de que seus conhecimentos poderiam ser adquiridos por qualquer interessado no ofício, sem a necessidade de seus fundamentos serem ministrados em escolas de Direito.

Necessidade esta reforçada por Amedeo Dalla Volta, da Universidade da Catania, ao comentar o Compêndio de Medicina Legal, de Attilio Cevidalli, ao dizer:

A necessidade de um compêndio, dedicado acima de tudo ao ensino, com particular respeito à Medicina Legal, esforço de um amplo e heterogêneo grupo de estudiosos, revela-se em uma sutil e convincente exposição doutrinária, inspirada no equilíbrio e na crítica, sem o defeito de um esquematismo rígido e artificial, fudamentando as bases de uma disciplina ${ }^{5}$.

E continuava: "trata-se de um patrimônio cultural imprescindível a um médico ou a um jurista culto".

É de suma importância esta argumentação de Dalla Volta, posto que o mesmo afirma com muita propriedade ser o livro de Cevidalli (e, obviamente, o seu autor, como ocorreria no Brasil posteriormente, conforme veremos adiante) o responsável por fundamentar as bases da Medicina Legal enquanto disciplina autônoma na Itália. O prefaciador, com 
agudeza de observação, antevê em um compêndio dessa magnitude, que reúne com método próprio todos os conhecimentos auridos pela disciplina, a forma mais correta de institucionalizar a matéria, mostrando à classe científica sua relevância, teórica e prática.

Este compêndio de Cevidalli, representante da "escola italiana" (em contraposição à escola francesa) de Medicina Legal, como também veremos adiante, entre outros méritos, servirá de base para todo o desenvolvimento da ciência médico-legal no Brasil na primeira metade do século passado. Escola italiana esta tão bem representada por outros expoentes como Carrara, Condronchi e Fedele, seguidores de Paulo Zacchia, considerado por muitos (em detrimento de Ambroise Paré) como o "pai da Medicina Legal" e autor da obra máxima em três volumes denominada "Questões médicolegais"1.

\section{O DESENVOLVIMENTO DA MEDICINA LEGAL NO BRASIL}

A "escola italiana", não só na Medicina Legal, como também no Direito (com a vigência do primeiro Código Penal Republicano de 1890 fortemente marcado pelo Direito Romano), deixará suas marcas no Brasil. Durante muito tempo, o modelo italiano (bem mais que a escola francesa) de Medicina Legal ditará as regras aos médicos legistas pátrios.

Também inspirada no modelo italiano, é na Bahia, com Raymundo Nina Rodrigues, Oscar Freire e Afrânio Peixoto (este mais adepto da doutrina germânica) que se irá desenvolver a primeira grande escola de Medicina Legal (ainda não considerada como uma verdadeira especialidade) no Brasil.

Nina Rodrigues, maranhense de nascimento, homem múltiplo e adepto das idéias de outro italiano famoso no campo da Medicina Legal - Cesare Lombroso -, pode ser considerado o introdutor no Brasil da assim chamada antropologia criminal, da antropometria de Bertillon e da frenologia.

Foi um estudioso em várias áreas, aproximando a Medicina Legal das Ciências Sociais com brilhantismo. Com os resultados de seus estudos propôs uma reformulação no conceito de responsabilidade penal, sugeriu a reforma dos exames médico-legais e foi pioneiro da assistência médico-legal a doentes mentais, além de defender a aplicação da perícia psiquiátrica não apenas nos manicômios, mas também nos tribunais. Incansável, analisou em profundidade os problemas do negro no Brasil, fazendo escola no assunto. Entre seus livros destacaram-se "As raças humanas e a responsabilidade penal no Brasil" (1894), em que propunha uma codificação penal para cada etnia, "O animismo fetichista dos negros da Bahia" (1900) e "Os africanos no Brasil (1932)".

Há que se dizer, todavia: sua obra fundamental, "Mestiçagem, degenerescência e crime" (1899), deixa à mostra a influência lombrosiana, na medida em que busca provar a tendência de negros e mestiços para a degeneração e o crime. Duas outras obras suas ("Antropologia patológica: os mestiços" e "Degenerescência física e mental entre os mestiços nas terras quentes") não deixam dúvidas acerca do caráter racista e ultrapassado de suas teses. Para ele, negros e mestiços eram a causa básica da inferioridade brasileira.

Influenciado pelo positivismo sociológico, no entanto, é necessário salientar que a obra de Nina Rodrigues (com mais de 60 títulos) é de suma importância para o desenvolvimento tanto da antropologia forense como da criminalística em nosso país - fazendo parte do contexto de uma época e, como tal, devendo ser analisada, com os questionamentos devidos, porém, de forma isenta, sem parti pris.

A influência dos aspetos sociológicos na Medicina Legal era tão grande que, em 1895, em uma reforma de ensino, as cadeiras de Higiene e de Medicina Legal, criadas pela reforma anterior (de 1891), foram fundidas em uma só, a de "Medicina Pública" - somente sendo separadas tempos depois ${ }^{3}$.

Entretanto, será Oscar Freire, discípulo de Nina Rodrigues, no ano de 1918, quem irá trazer para São Paulo os ensinamentos desta "escola baiana", por meio de uma atividade docente, de pesquisa e pericial, como se pode ver em seus inúmeros trabalhos reunidos em volume dedicado tão somente às perícias, com pareceres médicolegais brilhantes que nos servem de modelo até os dias de hoje ${ }^{6}$.

Podemos, sem sombra de dúvida, considerar a vinda de Oscar Freire, com a instalação da cadeira de Medicina Legal junto à recém criada Faculdade de Medicina e Cirurgia de São Paulo, o marco de constituição da então disciplina como uma verdadeira especialidade médica no Brasil.

Até então, a disciplina de Medicina Legal em São Paulo compunha apenas o currículo do curso de Direito, tendo sido ministrada, na Faculdade do Largo de São Francisco, entre outros, pelo bacharel em Direito Alcântara Machado e pelo médico Antônio Almeida Prado ${ }^{7}$. Nessa época, as práticas periciais legitimadas pelo saber médico-legal faziam 
parte de um processo dinâmico que buscava sua afirmação e ansiava por sua institucionalização como disciplina autônoma e como verdadeira especialidade iniciada por Oscar Freire.

$$
\text { O "personagem-chave" }
$$

dessa institucionalização da especialidade a partir da Faculdade de Medicina será um discípulo de Oscar Freire - Flamínio Fávero. Formado na primeira turma da "Casa de Arnaldo", permaneceu vinculado a ela como preparador (o grau inicial da carreira docente) desde 1919, quando então se tornou professor substituto de Higiene e Medicina Legal. Em 1923, com a morte de Oscar Freire, assumiu a vaga de professor catedrático, saindo apenas por jubilamento em 1955. Ainda em 1923, a Cadeira de Medicina Legal seria desmembrada da Cadeira de Higiene e, em 1931, Fávero organizaria o "Instituto Oscar Freire", reunindo as cátedras de Medicina Legal, Deontologia Médica e Medicina Social e do Trabalho ${ }^{7}$. A nova disciplina caminhava para o que Afrânio Peixoto denominou de "Medicina Social", agregando "a infortunística, os acidentes de trabalho, a avaliação de incapacidades, o prognóstico legal, a invalidez operária, o seguro social, que contam imensamente mais que os casos contados criminais. O termo 'Medicina' já é estreito: as perícias de todo gênero pedem recurso a toda ciência: os técnicos de todo o gênero serão os peritos. O médico amplia suas preocupações: médico 'social'. E não só os médicos, outros técnicos 'sociais"'’3.

No campo científico, a Medicina Legal será consolidada, por sua expressão institucional, por meio da criação de associações e sociedades, publicação de periódicos dedicados à disciplina, bem como a realização de eventos congregando todos os praticantes da especialidade ${ }^{7}$, notandose, no decorrer da década de 20 do século passado, uma "intensa atividade organizacional". A Sociedade de Medicina Legal e Criminologia de São Paulo, por exemplo, será instalada com o esforço de professores da Faculdade de Direito e da Faculdade de Medicina em 1921. Estes pioneiros, subseqüentemente, fundaram a revista Archivos da Sociedade de Medicina Legal e Criminologia de São Paulo - que circulou entre 1922 e 1924, ampliando seu espectro institucional e editorial a partir de 1929, agregando a Penitenciária do Estado como uma de suas co-responsáveis, adicionando novas seções, novos colaboradores e nova denominação: Revista de Criminologia e Medicina Legal ${ }^{7}$.

É assim que, a partir dessa consolidação da disciplina em nível institucional, pode-se perceber a disseminação dos conhecimentos na área médicolegal $e$, por conseguinte, conhecer o modus operandi dos peritos da época.

Toda essa pesquisa histórica, realizada por Salla e Marinho, deu-se no Fundo do Poder Judiciário de Bragança Paulista, e os autores descrevem as condições das perícias realizadas à época, após análise de "oito processos criminais relativos a casos de defloramento, aborto, tentativa de suicídio e lesões corporais" . Os documentos examinados referem-se ao período de 1899 a 1915, e apenas um inquérito policial datado de 1937. A descrição feita por eles evidencia as precárias condições de atuação dos peritos, a inexistência de espaços ou qualificação adequados e, conseqüência óbvia desse estado de quase inanição, "a irrelevância dos laudos no julgamento dos processos ou andamento dos inquéritos"'. Os próprios autores citam que "um dos elementos mais evidentes dessa precariedade refere-se ao perfil dos peritos designados para a realização das perícias, procedentes em sua grande maioria de ocupações distintas ou apenas correlatas ao campo específico da Medicina, tais como 'coronéis' ou farmacêuticos"7. Apenas mais tarde, médicos de formação clínica serão convocados a participar das perícias.

Os mesmos autores, a partir de sua pesquisa histórica em Bragança Paulista, anotam a evolução do processo de crescimento da Medicina Legal a partir de exigências da própria sociedade. Afirmam eles:

Contudo, a perspectiva de uma intervenção social mais direta, legitimada pelo saber médicocientífico, havia encontrado espaço no ambiente social de Bragança desde o início do século $X X$. Em 1906, por exemplo, o delegado de polícia, Euclides da Silva, dirigiu um ofício à Câmara de Vereadores no qual solicitava a instalação de um gabinete antropométrico, conforme publicação do jornal A Notícia, trecho transcrito a seguir:

\begin{abstract}
'Na Polícia,
Gabinete antropométrico

Um officio

No louvável intento de dotar nossa cidade de uma delegacia de polícia que, mais ou menos, satisfaça à complexas exigências duma repartição, o sr. Dr. Euclides Silva, como delegado, dirigiu a câmara municipal desta cidade um officio solicitando um auxílio para a fundação de um gabinete antropométrico. Esta medida fará, si for levada a effeito, que a nossa cidade, exceptuando a capital, seja a única do Estado dotada de tal melhoramento... ${ }^{\prime}$.
\end{abstract}

\section{MEDICINA LEGAL: TRADIÇÃO ORAL}

Como dissemos anteriormente, Oscar Freire, 
oriundo da Faculdade de Medicina da Bahia, discípulo de Nina Rodrigues, chegou a São Paulo em 1918, a fim de ocupar a Cadeira de Medicina Legal. Contou inicialmente com dois assistentes: Pedro Dias da Silva e Flamínio Fávero. Logo depois de um ano, Dias da Silva viria a ocupar a direção da Faculdade de Medicina, afastando-se da Medicina Legal, para ultimar os acordos com a Fundação Rockfeller, implantando uma reforma curricular nos moldes preconizados pelos americanos. Com isso, Flamínio Fávero passaria a ser o assistente direto de Oscar Freire.

Percebe-se claramente, nesse breve resumo histórico, a forma como os conhecimentos médicolegais eram transmitidos em meados do século passado. Na prática, ex-alunos e discípulos de mestres recebiam o legado de seus antecessores e os repassavam a seus seguidores - de forma verbal, em aulas magistrais, ou, eventualmente, por meio de livros por eles publicados e contendo de forma prática e teórica seus ensinamentos.

Além das obras publicadas por Nina Rodrigues, mencionadas anteriormente, as que mais se aproximavam de um texto erudito foram "Tratado de Medicina Legal", de Agostinho de Souza Lima (em 1923) e "Medicina Legal" de Afrânio Peixoto (também já mencionado acima, em 1938). Esta última, nitidamente inspirada no "Compêndio de Medicina Legal" de Atílio Cevidalli, como se pode notar nas ilustrações referentes aos tipos de hímens no capítulo dedicado ao estudo da sexologia forense, obviamente com acréscimos de contribuições brasileiras, como a sua própria classificação dos tipos himenais dividindo-os em três grandes grupos: os acomissurados, os comissurados e os atípicos. Apesar dessas referências, Peixoto não se furta, no entanto, a criticar os mestres, pois propôs uma classificação nova, justamente por considerar aquela ensinada por Nina Rodrigues "muito complicada"2.

Já Oscar Freire preferia ensinar pela prática. Seu opúsculo "Exames e Pareceres MedicoLegaes" (de 1926) é simplesmente brilhante como método de ensino teórico-prático. Os modelos de laudos e pareceres que formam o corpo da obra são altamente elucidativos e tornaram-se paradigmas da boa prática forense. É dele, por exemplo, a afirmação (no exame que abre o livro) de que a gravidez é um sinal de certeza de conjunção carnal. A título de ilustração, diz: "Seria ridículo ainda discutir no caso em estudo a existência de defloramento, em presença de gravidez comprovada com franca permeabilidade himenal"'

O próprio Oscar Freire dividiu a evolução da Medicina Legal no Brasil em três fases: 1) estrangeira; 2) de transição; 3) de nacionalização. Para ele a fase estrangeira vai desde o fim do período colonial até o ano de 1877 , no qual Souza Lima assume a cátedra de Medicina Legal da Faculdade de Medicina que pertence hoje à Universidade Federal do Rio de Janeiro. Segundo Higino de Carvalho Hercules, "A primeira publicação dessa fase data de 1814, e era um documento em que Gonçalves Gomide, médico e senador do Império, contestava um parecer dado por dois outros profissionais, Antônio Pedro de Souza e Manuel Quintão da Silva, em que afirmavam ser santa uma rapariga da comarca de Sabará, na capela de Nossa Senhora da Piedade da Serra"1.

Àquela época, os juízes brasileiros não tinham a obrigação de ouvir peritos antes de proferirem a sentença. Continua o autor: "Tal dever só Ihes seria imposto com o advento do Código Penal Brasileiro, em 1830. No artigo referente ao homicídio, esse código estipulava que 'o mal se julgará mortal a juízo dos facultativos"'1.

Hercules aduz:

No ano de 1832, ocorrem dois fatos importantes para a Medicina Legal brasileira. É regulamentado o processo penal, estabelecendo-se as regras para os exames de corpo de delito, criandose, assim, a perícia profissional. Além disso, as antigas escolas médico-cirúrgicas, criadas por decreto de D. João VI em 1808, na Bahia e no Rio de Janeiro, são transformadas em faculdades de medicina oficiais, sendo criadas, em ambas, uma cadeira de Medicina Legal. Como, para obter o grau de doutor, os alunos eram obrigados a defender uma tese, alguns optavam por desenvolvê-la na área da Medicina Legal. Embora se constituíssem em meras cópias de tratados europeus, abriram caminho para a ampliação das pesquisas em Medicina Forense ${ }^{1}$.

A passos lentos, a Medicina Legal vai se desenvolvendo no Brasil. A primeira publicação de uma necropsia medico-legal se dá em 1835, quando Hércules Otávio Muzzi, cirurgião da família imperial, relata a "Autopsia do Exmo.Sr. Regente João Bráulio Muniz, realizada 22 horas após a sua morte"1. Em 1854, o Conselheiro Jobim, primeiro catedrático de Medicina Legal da Faculdade de Medicina do Rio de Janeiro, uniformiza a prática dos exames médico-legais a pedido do Ministro da Justiça. Em 1856, quatro médicos passam a assessorar a Secretaria de Polícia da Corte - dois deles sendo encarregados de executar os exames de corpo de delito e, os outros dois, denominados "consultantes", eram professores da Faculdade responsáveis pelos exames toxicológicos. 
Somente em 1900 é que a assessoria médica da Polícia da Corte será transformada por decreto em Gabinete Médico-Legal, contando com um serviço de identificação antropométrica e passando a fazer também exames psiquiátricos ${ }^{1}$.

Serviço de assessoria similar ao do Rio de Janeiro foi criado em São Paulo em 1885, e regulamentado pela Lei $\mathrm{n}^{\circ} 18$ em abril de 1886, como Serviço Médico Policial da Capitale. Em 1906, essa instituição tem seu nome alterado para Gabinete Médico-Legal. Armando de Salles Oliveira, interventor em São Paulo à época do Estado Novo, cria o Conselho Médico-Legal (reunindo os laboratórios de Toxicologia, Anatomia Patológica e Microscopia e os 13 Postos MédicoLegais do interior do Estado), por meio do Decreto $n^{\circ} 6118$. Pouco antes disso, em 1903, por influência de Afrânio Peixoto, o Governo Federal baixa o Decreto 4.864, que estabelecia normas detalhadas para a descrição e conclusão das perícias médicas, sugerindo um protocolo de necropsias semelhante ao proposto pelo alemão Virchow - na tentativa de colocar freio no que o próprio Peixoto denominava de "monstruosidades alcunhadas de termos de autópsias, autos de corpo de delito confusos, desordenados, incoerentes, dando um triste atestado de incompetência profissional e prejudicando os interesses da justiça"'.

A fase de transição a que se refere Oscar Freire tem início em 1877, quando o ensino da Medicina Legal assume caráter prático com aulas de tanatologia forense em necrotérios oficiais por Agostinho José de Souza Lima. A fase de nacionalização é marcada pela posse de Raimundo Nina Rodrigues, em 1895, como catedrático de Medicina Legal da Faculdade de Medicina da Bahia'.

Falta, neste modelo esquemático proposto por Freire, até por ser posterior a ele, uma fase que poderíamos denominar de "institucionalização" - onde o conhecimento e o saber médico-legal se consolida e passa a ser organizado de forma sistemática.

Flamínio Fávero: a institucionalização da medicina legal

Como dissemos anteriormente, o melhor discípulo de Oscar Freire - Flamínio Fávero se tornará o responsável por essa organização sistemática do conhecimento médico-legal no Brasil, aumentando sobremaneira o legado de seu mestre, que, como tal, nunca deixou de reconhecer. No prefácio à $4^{\text {a }}$ edição de sua obra seminal
"Medicina Legal" (atualizada por conta do então novo Código Penal de 1940), Fávero afirma: "meu propósito foi dizer o reconhecimento de discípulo à memória veneranda de Oscar Freire, o mestre inesquecível que me iniciou no magistério superior". $E$, sobre essa obra que se tornaria fundamental para a consolidação da medicina forense brasileira, Alcântara Machado teceu os seguintes comentários em carta endereçada ao autor:

"Régio presente de Natal acaba o amigo de fazer aos estudantes e aos mestres da especialidade. Esse padrão de glória para o autor, para a escola de Nina Rodrigues e de Oscar Freire, para a cultura paulista, para a ciência brasileira! Sua obra singularmente feliz na limpeza e propriedade da linguagem, na adequação da teoria à prática, na erudição discreta, na abundância da documentação. Outra não há que a sobreexceda, na literatura nacional ou estrangeira, em qualidades ou virtudes didáticas. Afirmo-o autorizado por uma experiência de quarenta anos de professorado. Pode o sr. fazer suas as palavras do poeta latino: exegi monumentum aere perennius. Orgulho-me de sua obra como paulista. Dela me ufano, como o mais humilde dos discípulos de Nina Rodrigues" 9.

Não há, em nossa opinião, melhor descrição do legado de Flamínio Fávero à Medicina Legal brasileira: monumental e perene. Monumental por conter todos os fundamentos da nova disciplina hierarquizados de forma simples, porém soberba. Perene - de vez que até hoje seus ensinamentos são seguidos paripassu por todos aqueles que se dedicam à profissão, à especialidade e ao ensino da técnica e da doutrina médico-legal no Brasil. Ou seja: é a partir da publicação de Medicina Legal de Flamínio Fávero, livro premiado tanto pela Faculdade de Medicina da Universidade de São Paulo (FMUSP), como pela Sociedade de Medicina Legal e Criminologia de São Paulo, que se dá, efetivamente, a institucionalização da especialidade em São Paulo e no Brasil. E mais: é com o lançamento dessa obra (especialmente em seu terceiro volume) que se incorpora de vez por todas a Deontologia Médica e a Medicina Profissional, a Ética Prática em sentido mais amplo, ao campo de atuação e ensino da Medicina Legal.

Fávero percebeu e antecipou que para a institucionalização completa de um novo saber não bastava a disseminação de conhecimentos por meio apenas de ensino verbal (ministrar aulas) ou prático (a realização de perícias). Estas formas de disseminação da ciência são por si mesmas efêmeras, se perdem no tempo (ou cristalizam e depois fossilizam o conhecimento adquirido, protelando os avanços científicos). Para consolidar 
a especialidade, fortalecê-la, Fávero intuiu ser necessário documentá-la por escrito - fundar suas bases teóricas, sedimentar seu campo de atuação, incluindo (como já dissemos) a ética prática normativa e também a medicina social e do trabalho. $\mathrm{E}$, além disso, avançar na produção de novos conhecimentos, dando visibilidade às teses que eram produzidas na Faculdade de Medicina da USP, tendo sido orientador de cerca de 160 delas. $E$ é isso que seu "Medicina Legal", por sua magnitude, clareza e sólida base científica, representa, sem exageros: a fundação da Medicina Legal brasileira - no sentido de que todos os seus alicerces fundamentais, responsáveis por manter em pé o edifício (com suas normas, suas regras, suas técnicas e premissas básicas), ali se encontram. Nesse sentido, o Instituto Oscar Freire, prédio ligado à Faculdade de Medicina da USP à Avenida Dr. Arnaldo, cumpre hoje os desígnios de Fávero, visto que abriga em seu seio, como departamento, o estudo da Medicina Legal, da Ética Médica e da Bioética, bem como da Medicina Social e do Trabalho.

Por fim, após a institucionalização da especialidade por Flamínio Fávero, a Medicina Legal passa por uma segunda etapa, a de sua profissionalização com a criação do primeiro programa de residência médica no país, na Faculdade de Medicina da USP. Mas essa é uma história que demanda vários capítulos e um novo artigo específico.

Miziara ID, Miziara CSMG, Muñoz D. The institutionalization of Forensic Medicine in Brazil. Saúde, Ética \& Justiça. 2012;17(2):66-74.

ABSTRACT: The authors described the history of forensic medicine in Brazil, since its institution at the Bahia School of Medicine by Nina Rodriguez, to the contribution of Oscar Freire in bringing the scientific forensic work to Sao Paulo and to the University of Sao Paulo School of Medicine, where the subject became, in time, an independent discipline, by the hands of Dr. Freire's disciple, Flaminio Fávero.

KEYWORDS: Forensic medicine/history; Forensic medicine/education; Educational, medical, undergraduate/ history.

\section{REFERÊNCIAS}

1. Hercules HC. Medicina legal - texto e atlas. São Paulo: Atheneu; 2008.

2. Peixoto A. Medicina legal. Rio de Janeiro: Livraria Francisco Alves; 1938.

3. Peixoto A. Novos rumos da medicina legal. Rio de Janeiro: Companhia Editora Nacional; 1938.

4. Souza Lima AJ. Tratado de medicina legal. Rio de Janeiro: Grande Livraria Leite Ribeiro; 1923.

5. Cevidalli A. Compendio di medicina legale. 2a ed. Milano: Societa Editrice Livraria; 1928.

6. Freire O. Exames e pareceres medico-legaes. São Paulo: Livraria Acadêmica; 1926.

7. Salla F, Marinho MGSMC. Medicina legal e perícias médicas em processos criminais. Constituição de saberes e aplicação de procedimentos médicolegais. Campo, personagens e práticas periciais: São Paulo e Bragança.(1890-1940). In: Anais do XIX Encontro Regional de História: Poder, Violência e Exclusão - ANPUH/SP - USP; 2008 set 08-12 [citado 10 nov .2012]. Disponível em: http://www.anpuhsp. org.br/sp/downloads/CD\%20XIX/PDF/Autores\%20 e\%20Artigos/Fernando\%20Salla\%20Maria\%20 Gabriela\%20S.\%20M.\%20C.\%20Marinho.pdf

8. Histórico do Instituto Médico Legal [citado 10 nov. 2012]. Disponível em http://www.polcientifica.sp.gov. br/institucional_IML_historico.asp .

9. Fávero F. Medicina legal. São Paulo: Martins Editora; 1973. 